Note

\section{Production of Mannosylerythritol by Candida sp. KSM-1529}

\author{
Tohru Kobayashi, Susumu Ito \\ and Kikuhiko Окамото
}

\author{
Tochigi Research Laboratories of Kao Corporation, \\ 2606 Akabane, Ichikai, Haga, Tochigi \\ 321-34, Japan
}

Received January 9, 1987

It has been demonstrated that Candida sp. B-7 produces a unique glycolipid, mannosylerythritol lipid (MEL), during the fermentation of alkanes. ${ }^{1)}$ This glycolipid is a mixture of the $2^{\prime}, 6^{\prime}$-di- $O$-acyl $\left(\mathrm{C}_{8} \sim \mathrm{C}_{14}\right)$ esters of $4-O-\beta$-Dmannosyl-D-erythritol (ME). The biological significance of MEL produced by the yeast may be related to the mechanism for the uptake of alkanes. In fact, Torulopsis bombicola produces sophorose lipid as a growth stimulant when it is grown on insoluble alkanes. ${ }^{2,3)}$

Recently, we found that Candida sp. KSM-1529 produces a large amount of ME under certain growth conditions. In this paper, we describe these growth conditions and some biological characteristics of ME.

Candida sp. KSM-1529 (Strain b-1) is one of a series of mutants derived from the parental Candida sp. S-10 ${ }^{4}$ which produces itaconate from alkanes, and was kindly provided by Drs. T. Tabuchi and T. Nakahara of University of Tsukuba, Japan. Candida sp. KSM-1529 was recognized as a producer of MEL, at concentrations from 35 to $50 \mathrm{~g} / \mathrm{l}$, when it was grown in a broth which contained plant oils or alkanes (our laboratory, unpublished data). The production of ME by this yeast was first suggested by the observation that replacement of plant oils or alkanes with glucose caused the accumulation of an unknown polyol in the medium. The formation of ME was ascertained by thin-layer chromatography (Silica Gel G) with 1butanol-acetic acid-ethyl ether-water $(9: 6: 3: 1, \mathrm{v} / \mathrm{v})$ as a solvent. The ME spot was located by spraying the plates with Yoda's reagent, ${ }^{5)}$ and corresponded to an $R f$ value of 0.14 . ME was measured by high-performance liquid chromatography on a Hitachi 655LC system with a TSK gel G. Oligo PW column (Toyo Soda Kogyo Co., Ltd.) and a Shodex RI-SE31 detector (Showa Denko Co., Ltd.). Elution was done with $5 \%(\mathrm{v} / \mathrm{v})$ methanol at a flow rate of $0.7 \mathrm{ml} / \mathrm{min}$, at room temperature.

The seed medium contained (per liter) $25 \mathrm{~g}$ of glucose, $5 \mathrm{~g}$ of casamino acids, $0.5 \mathrm{~g}$ of $\mathrm{KH}_{2} \mathrm{PO}_{4}, 0.5 \mathrm{~g}$ of $\mathrm{MgSO}_{4} \cdot 7 \mathrm{H}_{2} \mathrm{O}$, and $0.5 \mathrm{~g}$ of yeast extract, and was made up with distilled water; it was $\mathrm{pH} \mathrm{6.0.} \mathrm{The} \mathrm{fermentation}$ medium for the production of $\mathrm{ME}$, also $\mathrm{pH} 6.0$, contained (per liter) $100 \mathrm{~g}$ of glucose, $5 \mathrm{~g}$ of casamino acids, $0.1 \mathrm{~g}$ of $\mathrm{KH}_{2} \mathrm{PO}_{4}, 0.2 \mathrm{~g}$ of $\mathrm{MgSO}_{4} \cdot 7 \mathrm{H}_{2} \mathrm{O}$, and $0.5 \mathrm{~g}$ yeast extract, and was made up with distilled water. Complete fermentation medium $(100 \mathrm{ml})$ was placed in $500-\mathrm{ml}$ Sakaguchi flasks and incubated aerobically at $26^{\circ} \mathrm{C}$ for one week on a reciprocal shaker ( 125 strokes $/ \mathrm{min}$ ) with $2 \%$ of a 2 -day-old seed culture.

ME was isolated from the spent medium by removing the cells by centrifugation, then putting one liter of the supernatant, acidified to $\mathrm{pH} 4.5$ with acetic acid, on a column of activated charcoal $(8 \times 50 \mathrm{~cm})$. The column was washed with 6.01 of distilled water and then eluted with $25 \%(\mathrm{v} / \mathrm{v})$ ethanol, and fractions were checked for the presence of ME by thin-layer chromatography. The fractions containing the material were pooled and concentrated in vacuo below $50^{\circ} \mathrm{C}$. The resulting concentrate $(16.2 \mathrm{~g})$ was further purified by chromatography on an activated charcoal column $(5 \times 55 \mathrm{~cm})$ with $10 \%(\mathrm{v} / \mathrm{v})$ ethanol as an eluent. The eluted material was concentrated in vacuo to yield $14.9 \mathrm{~g}$ of $\mathrm{ME}$, which was pure by thin layer and high-performance liquid chromatographies. The resulting material was colorless and transparent, and contained $8.9 \sim 17.0 \%$ water as estimated by the KarlFisher method.

The structure of the isolate was characterized by ${ }^{13} \mathrm{C}$ NMR, FD-MS spectrometry, infrared (IR) spectrophotometry and other methods. NMR ${ }_{\mathrm{TMS}}^{\mathrm{DMSO}-d_{6}} \delta_{\mathrm{C}}$ at $60^{\circ} \mathrm{C}$ were: 101.3 (C-1' $\beta$-D-mannopyranoside), 78.4 (C-5'), 74.6 (C$\left.3^{\prime}\right), 73.3$ (C-2), 72.1 (C-4, $O$-substituted $\mathrm{C}$ of erythritol), 71.6 (C-3), $71.5\left(\mathrm{C}-2^{\prime}\right), 68.2\left(\mathrm{C}^{\prime} 4^{\prime}\right), 64.2$ (C-1), $62.4\left(\mathrm{C}^{\prime} 6^{\prime}\right)$ and 39.7 (methyl $\mathrm{C}$ of DMSO- $d_{6}$ ). Results from FD-MS gave the following $m / z$ values: $285(\mathrm{M}+1)^{+}, \quad 569$ $(2 \mathrm{M}+1)^{+}$. Infrared spectrophotometry gave the following values for IR $\gamma_{\max }(\mathrm{NaCl}) \mathrm{cm}^{-1}: 3400(\mathrm{OH}), 2940$ and 2840 $\left(-\mathrm{CH}_{2}-\right), 1075(-\mathrm{O}-), 1050$ (primary $\left.\mathrm{OH}\right), 898$ ( $\beta$-configuration of mannopyranoside). When the isolate was acid-hydrolyzed, high-performance liquid chromatography yielded two peaks which corresponded to mannose

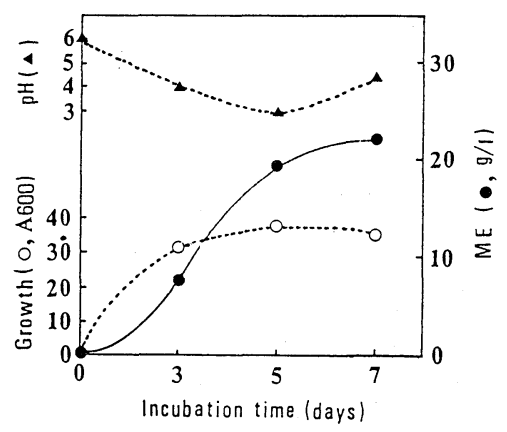

FIG. 1. Production of ME by Candida sp. KSM-1529.

Experimental conditions are described in the text. Cell growth was monitored by measurement of the absorbance at $600 \mathrm{~nm}\left(A_{600}\right)$ of the medium at appropriate dilutions, made with chilled water. 
and erythritol with a stoichiometry of almost $1: 1$. In addtion, the isolate could be hydrolyzed by $\beta$-mannosidase from Achatina fulica, but not by $\alpha$-mannoidase from jack beans. These results coincided with those obtained after saponification of MEL. The structure of 4- $O-\beta$-D-mannosyl-D-erythritol (ME), as derived by us, is probably the same as that reported by Boothroyd et $a l .{ }^{6)}$ who isolated it from cultures of the fungus Ustilago, and that of ME synthesized chemically by Gorin $e t \mathrm{al}^{7}{ }^{7}$

As shown in Fig. 1, the greatest yield of ME was observed after 7 days of incubation (about $22 \mathrm{~g} / \mathrm{l}$ ), while the cell mass reached a plateau after 3 days. Mannose or fructose could replace glucose entirely, and glycerol, erythritol, mannitol, or galactose could partially replace glucose, to give a yield of ME of $7.0 \sim 18.1 \mathrm{~g} / \mathrm{l}$. However, other usable carbohydrates such as ribose, arabinose, rhamnose, sorbitol, and dulcitol did not support the accumulation of ME in the medium.

These results suggest indirectly that extracellular lipids with the surfactant-like structures are essential for the uptake of alkanes by microorganisms, and that the function of the lipids may be attributed to their emulsifying activities in the oil-water phase. In fact, microorganisms which grow on alkanes excrete surfactant-like materials, such as trehalose lipid, ${ }^{81}$ peptide lipid, ${ }^{9)}$ and rhamnose lipid, ${ }^{10)}$ in addition to the sophorose lipid produced by Torulopsis bombicola. ${ }^{3.111}$ Therefore, ME is probably synthesized by Candida sp. KSM-1529 as the direct precursor of MEL. ME is thought to be acylated, only when the organism is grown on alkanes or triglycerides, and then be excreted into the extracellular environment to emulsify the insoluble substrates.

Acknowledgment. We thank Mrs. H. Inaoka and $\mathrm{H}$. Sonohara for their expert technical assistance.

\section{REFERENCES}

1) H. Kawashima, T. Nakahara, M. Ozaki and T. Tabuchi, J. Ferment. Technol., 61, 143 (1983).

2) S. Inoue and S. Ito, Biotechnol. Lett., 4, 3 (1982).

3) S. Ito and S. Inoue, Appl. Environ. Microbiol., 43, 1278 (1982).

4) T. Tabuchi, T. Sugisawa, T. Ishidori, T. Nakahara and J. Sugiyama, Agric. Biol. Chem., 45, 475 (1981).

5) A. Yoda, Nippon Kagaku Kaishi, 73, 18 (1952).

6) B. Boothroyd, J. A. Thorn and R. H. Haskins, Can. J. Biochem. Physiol., 34, 10 (1956).

7) P. A. J. Gorin and A. S. Perlin, Can. J. Chem., 39, 2474 (1961).

8) T. Suzuki, K. Tanaka, T. Matsubara and S. Kinoshita, Agric. Biol. Chem., 33, 1619 (1969).

9) T. Iguchi, I, Takeda and H. Osawa, Agric. Biol. Chem., 33, 1657 (1969).

10) S. Itoh and T. Suzuki, Agric. Biol. Chem., 36, 2233 (1972).

11) J. F. T. Spencer, P. A. J. Gorin and A. P. Tulloch, Antonie van Leeuwenhoek J. Microbiol. Serol., 36, 129 (1970). 